\title{
Knowledge about Symptoms and Risk Factors of Osteoporosis among Adult Women in Cairo, Egypt
}

\author{
Rasha S. Hussein, Maha M. Wahdan
}

Department of Community, Environmental and Occupational Medicine, Faculty of Medicine, Ain Shams University, Cairo, Egypt.

Submitted:30-07-2020 Revised:24-08-2020

Accepted:25-08-2020

Abstract

Background: Osteoporosis (OP) is a bone condition that weaken bone over time, making it easier to break. Objectives: The study aimed to assess knowledge level about symptoms and risk factors for osteoporosis among adult women in Cairo, and to identify factors influencing their knowledge level.Method: Cross-sectional study was carried out among sample of Egyptian women aged 18 and more, living in Cairo who agree to participate and fulfill an online structured questionnaire using Osteoporosis Knowledge Assessment Tool (OKAT)Results: A sample of 414 adult women answered the on-line questionnaire with mean age $(35.6 \pm 10.6)$. All surveyed women were familiar with OP, the predominant source of information was mass media $(48.3 \%)$, followed by friends $(37 \%)$, academic study $(32.9 \%)$, lastly from physicians $(21.3 \%)$. Mean total OKAT score was $10.5 \pm 3.4(0.0-18.0)$; and the total knowledge percent score was $52.3 \pm 17.1(0.0-90.0)$. Less than half of the surveyed women $(41.5 \%)$ scored a percentage score $(\geq 60 \%$ correct answer). Knowledge level had a significant association with women working status and educational level which act also as a significant predictor for the OP knowledge level.More correct answers were recorded from that receiving information from mass media, followed by doctors, academic research, lastly friends.Conclusion: Poor knowledge about osteoporosis has been identified among adult studied women in Cairo. Developing successful health education campaigns may be beneficial in improving awareness about osteoporosis and its risk factors; and consequently, adopting healthy behavior that prevents or decreases bone loss.

Keywords: Adult women, Knowledge, OKAT, Osteoporosis, Risk factors

Corresponding author:MahaMagdyEmail: drmaha_wahdan@med.asu.edu.eg

\section{Introduction}

Osteoporosis (OP) is a skeletal condition that affect the mineral density of bone, deteriorate the bone fragility, and increase bone fracture risk. ${ }^{1}$ Worldwide, there is a significant public health issue that affects 200 million women and causes more than 8.9 million fractures per year. It is estimated that worldwide an osteoporotic fracture occurs every 3 seconds. At 50 years of age, one in three women will suffer a fracture in their remaining lifetime. For women this risk is higher than the risk of breast, ovarian and uterine cancer combined. In women over 45 years of age, osteoporosis accounts for more days spent in hospital than many other diseases, including diabetes, myocardial infarction and breast cancer. ${ }^{2}$

In Egypt, based on previous studies, the prevalence of OP was $28.4 \%$ in women, furthermore, the prevalence of $\mathrm{OP}$ in 
postmenopausal women in rural areas of

Upper Egypt was higher reaching $47.8 \% .^{3,4}$

Table (1):Socio-demographic Characteristics of The Studied Adult Women $(N=414)$.

\begin{tabular}{|c|c|c|c|}
\hline & & $\mathbf{N}$ & \\
\hline Age $[$ mean $\pm S D$ & $n-\operatorname{Max})]$ & $35.6 \pm 10.6$ & \\
\hline Marital status & Single & 113 & 27.3 \\
\hline & Married & 278 & 67.1 \\
\hline & Divorced & 16 & 3.9 \\
\hline & Widow & 7 & 1.7 \\
\hline Children number & $a n \pm S D(\operatorname{Min}-\operatorname{Max})]$ & $2.1 \pm 1.2$ & \\
\hline Educational level & Secondary \& below & 25 & 6.0 \\
\hline & University & 211 & 51.0 \\
\hline & postgraduate & 178 & 43.0 \\
\hline Working status & Not working & 138 & 33.3 \\
\hline & Working & 276 & 66.7 \\
\hline
\end{tabular}

Osteoporosis is a silent disease. But, in the same time it is a preventable and treatable illness. OP Prevention include early identification of risk factors..$^{5}$ Risk factors of Osteoporosis include both Modifiable and nonmodifiable risk factors, the unmodifiable risk factors as being female, old age, ethnicity and in some conditions present of family history, ${ }^{6}$ modifiable risk factors include low dietary or supplementary intake of vitamin D and calcium, low body weight, falls, lack of physical activity, smoking and alcohol intake and prolonged intake of corticosteroids and proton pump inhibitors. ${ }^{2}$ In a study conducted atZagazig District Egypt results showed adult women awareness about risk factors and preventative measures was very low, with about one-third having unsatisfactory levels of awareness and a significant association was found between levels of awareness and socio-demographic factors such as income, place of residence and type of occupation. ${ }^{6}$ Another study conducted among a sample of adult Egyptian women to assess their awareness about nutritional risk factors and protective factors of OP results showed that awareness about the consumption of milk, milk products, leafy vegetables and about the harmful effect of the carbonate beverages was very low and about half of the studied group were aware about the beneficial effect of the physical exercise. ${ }^{7}$ Another study conducted in China showed that the overall awareness score OP was $67.8 \%$ and Lower family income and education level were significantly associated with lower overall awareness score. ${ }^{8}$

Table (2):Previous Information about Osteoporosis and Its Sources $(\mathrm{N}=\mathbf{4 1 4})$.

\begin{tabular}{lrc}
\hline & $\mathbf{N}$ & $\mathbf{\%}$ \\
\hline $\begin{array}{l}\text { Previous information } \\
\text { about osteoporosis }\end{array}$ & 414 & 100.0 \\
\hline Source of information & & \\
\hline - Mass media & 200 & 48.3 \\
- Friends & 153 & 37.0 \\
- Academic study & 136 & 32.9 \\
- Physicians & 88 & 21.3 \\
\hline
\end{tabular}

As the awareness about OP risk and protective factors plays the major role in OP prevention the International Osteoporosis Foundation (2011) creates preventive strategies which aimed to lessen the risk of osteoporotic fractures later. Named "Three stages to unbreakable bones" itsaim was to raise the awareness about the importance of maintaining sufficient daily levels of vitamin D, calcium, protein, and physical activity to maintain bone health, at all ages. ${ }^{9}$

Many researches in various populations used Osteoporosis Knowledge Assessment 
Tool (OKAT) as a validated questionnaire towards OP, and its risk factors. ${ }^{10,11}$ But, as to evaluate the awareness and attitudes Table (3): Responses of Studied Adult Women towards OKAT Items (N = 414).

\begin{tabular}{|c|c|c|c|}
\hline OKAT items & No & Yes & Don't know \\
\hline $\begin{array}{l}\text { Osteoporosis leads to an increased risk of bone fractures (correct } \\
\text { answer: yes) }\end{array}$ & $1(0.2)$ & $375(90.6)$ & $38(9.2)$ \\
\hline $\begin{array}{l}\text { Osteoporosis usually causes symptoms (e.g., pain) before fractures } \\
\text { occur (correct answer: } \mathrm{No} \text { ) }\end{array}$ & $13(3.1)$ & $329(79.5)$ & $72(17.4)$ \\
\hline $\begin{array}{l}\text { Having a higher peak bone mass at the end of childhood gives no } \\
\text { protection against the development of osteoporosis in later life. } \\
\text { (correct answer: yes) }\end{array}$ & $55(13.3)$ & $287(69.3)$ & $72(17.4)$ \\
\hline Osteoporosis is more common in men (correct answer: $\mathrm{No}$ ) & $297(71.7)$ & $16(3.9)$ & $101(24.4)$ \\
\hline Cigarette smoking can contribute to osteoporosis (correct answer: yes) & $33(8)$ & $203(49)$ & $178(43)$ \\
\hline $\begin{array}{l}\text { White women are at highest risk of fracture as compared to other races } \\
\text { (correct answer: yes) }\end{array}$ & $84(20.3)$ & $60(14.5)$ & $270(65.2)$ \\
\hline $\begin{array}{l}\text { A fall is just as important as low bone strength in causing fractures } \\
\text { (correct answer: yes) }\end{array}$ & $196(47.3)$ & $150(36.2)$ & $68(16.4)$ \\
\hline $\begin{array}{l}\text { By age } 80 \text {, the majority of women have osteoporosis (correct answer: } \\
\text { yes) }\end{array}$ & $18(4.3)$ & $283(68.4)$ & $113(27.3)$ \\
\hline $\begin{array}{l}\text { From age } 50, \text { most women can expect at least one fracture before they } \\
\text { die (correct answer: yes) }\end{array}$ & $70(16.9)$ & $218(52.7)$ & $126(30.4)$ \\
\hline Physical activity is beneficial for osteoporosis (correct answer: yes) & $17(4.1)$ & $316(76.3)$ & $81(19.6)$ \\
\hline $\begin{array}{l}\text { It is easy to tell whether I am at risk of osteoporosis by my clinical risk } \\
\text { factors (correct answer: yes) }\end{array}$ & $12(2.9)$ & $310(74.9)$ & $92(22.2)$ \\
\hline $\begin{array}{l}\text { Family history of osteoporosis strongly predisposes a person to } \\
\text { osteoporosis (correct answer: yes) }\end{array}$ & $75(18.1)$ & $199(48.1)$ & $140(33.8)$ \\
\hline $\begin{array}{l}\text { An adequate calcium intake can be achieved from two glasses of milk } \\
\text { a day (correct answer: yes) }\end{array}$ & $66(15.9)$ & $257(62.1)$ & $91(22)$ \\
\hline $\begin{array}{l}\text { Sardines and broccoli are good sources of calcium for people who } \\
\text { cannot take dairy products (correct answer: yes) }\end{array}$ & $41(9.9)$ & $316(76.3)$ & $57(13.8)$ \\
\hline Calcium supplements alone can prevent bone loss (correct answer: No) & $321(77.5)$ & $32(7.7)$ & $61(14.7)$ \\
\hline $\begin{array}{l}\text { Alcohol in moderation has little effect on osteoporosis (correct } \\
\text { answer: yes) }\end{array}$ & $5(1.2)$ & $274(66.2)$ & 135 (32.6) \\
\hline $\begin{array}{l}\text { A high salt intake is a risk factor for osteoporosis. } \\
\text { (correct answer: yes) }\end{array}$ & $51(12.3)$ & $116(28)$ & 247 (59.7) \\
\hline $\begin{array}{l}\text { There is a small amount of bone loss in the } 10 \text { years following the } \\
\text { onset of menopause (correct answer: } \mathrm{No} \text { ) }\end{array}$ & $25(6)$ & $233(56.3)$ & $156(37.7)$ \\
\hline $\begin{array}{l}\text { Hormone therapy prevents further bone loss at any age after } \\
\text { menopause (correct answer: yes) }\end{array}$ & $31(7.5)$ & $200(48.3)$ & $183(44.2)$ \\
\hline $\begin{array}{l}\text { There are no effective treatments for osteoporosis available in "Egypt" } \\
\text { (correct answer: yes) }\end{array}$ & $80(19.3)$ & $112(27.1)$ & $222(53.6)$ \\
\hline
\end{tabular}

far as we know, there are few studies in

Egypt which have investigated this area.

In the current study we aimed to assess knowledge level about symptoms, risk, and protective factors for osteoporosis among adult women in Cairo, through using validated Tool (OKAT) and to identify key factors that influence their knowledge level.

\section{Method}

Our target population was adult (aged 18 year and more) Egyptian women living in Cairo. As we did not have a sample frame and in addition to the method used to data collection (online questionnaire),

\section{The Egyptian Journal of Community Medicine \\ Vol. 39 \\ No. 2 \\ April 2021}


weinvited adult women to participate in our study. Thus, adult women who agreed to participate and fulfil the predefined criteria as Egyptian or aged 18 year and more were included in our study population.

Table (4): Distribution of OKAT Score, Percentages, and Categories among TheStudied Women $(N=414)$.

\begin{tabular}{|c|c|c|}
\hline & $\mathbf{N}$ & $\%$ \\
\hline $\begin{array}{l}\text { OKAT Score } \\
{[\text { mean }+S D} \\
(\text { Min }- \text { Max })]\end{array}$ & \multicolumn{2}{|c|}{$\begin{array}{c}10.5 \pm 3.4 \\
(0.0-18.0)\end{array}$} \\
\hline $\begin{array}{l}\text { OKAT Score percent } \\
{[\text { mean } \pm S D} \\
(\text { Min }- \text { Max })]\end{array}$ & \multicolumn{2}{|c|}{$\begin{array}{l}52.3 \pm 17.1 \\
(0.0-90.0)\end{array}$} \\
\hline $\begin{array}{l}\text { OKAT } \\
\text { correct }\end{array} \quad$ Poor $(<60 \%)$ & 242 & 58.5 \\
\hline $\begin{array}{l}\text { answer } \\
\text { categories }\end{array}$ Good $(\geq 60 \%)$ & 172 & 41.5 \\
\hline
\end{tabular}

Using Epi Info 7 software for sample size calculation, using confidence level of 95 percent and error margin of 5 percent, and reviewing previous study results ${ }^{12}$ showed that Osteoporosis Awareness Assessment results (based on cut-off point 60\%) was $79.4 \%$, based on these data, the minimum sample size required was 252 adult women. However, the total number of adult women responded to the on-line questionnaire were 414 women.

Data collection tool:Data were collected using Anonymous, self-administrated online questionnaire, delivered through different social media applications as (whatsapp, Facebook) to our study participants; the questionnaire was composed of 3sections:(1)Sociodemographic data (e.g. age, occupation, education...etc.). (2) Previous information and its source. (3) Knowledge about osteoporosis, symptoms and risk factors through using osteoporosis knowledge assessment test (OKAT) survey, a valid tool for assessing of knowledge of osteoporosis risk factors, ${ }^{(11)}$ it takes the form of 20 sentences, the first 12 evaluatethe knowledge of osteoporosis, next 4 sentences evaluate the attitude towards osteoporosis and the last 4 sentencesevaluate factors of osteoporosis prevention. every sentence has three options(yes, no, and I do not know).

The scoring of responses was performed as follows: one point was assigned for each right answer and zero for each wrong answer as well as for "do not know" answers. The overall OKAT score ranges from zero to 20.Then the score transformed into OKAT percentage by dividing the attained participant's score by 20. Then knowledge level was stratified into two categories according to cut off point of $60 \%$, the selection of this cut-off point based on reviewing the most relevant studies that use the same cut-off point to permit comparison between the results of the different studies. ${ }^{13,14,15}$

Arabic version According to Sayed-Hassan et al., the OKAT survey is acceptable and reliable. ${ }^{16}$

Ethical considerations:Approval was acquired from the ethical committee of the Faculty of Medicine, Ain Shams University, Egypt (Approval number: FMASU $R 30 /$ 2020). Filling the questionnaire by women is considered an approval to participate in the study. Privacy and confidentiality were maintained through anonymity of the questionnaire.

Data management and analysis:Data had been revised, coded, inserted on the computer, and examined using the Statistical Package for the Social Sciences (version 20). The mean, standard deviation (SD), and range values of quantitative data were addressed. Independent t-test was used for comparing quantitative variables between groups. Qualitative data is stated in terms of frequencies (n) and percentage\%). For test the association 
between qualitative variables, Chi-square and Fisher exact test were used.Binary logistic regression was used to explore the

effect of different Socio-demographic factors on the OP knowledge

Table (5): The association between Socio-demographic characteristics and knowledge level among the studied adult women $(\mathrm{N}=414)$.

\begin{tabular}{|c|c|c|c|c|c|c|}
\hline \multirow{3}{*}{ Variables } & \multicolumn{4}{|c|}{ OKAT categories } & \multirow{3}{*}{$P$ value } & \multirow{3}{*}{$\begin{array}{c}\text { COR } \\
(95 \% \mathrm{CI})\end{array}$} \\
\hline & \multicolumn{2}{|c|}{$\begin{array}{c}\text { Poor OKAT } \\
(<60 \% \text { correct } \\
\text { answer }) \\
\end{array}$} & \multicolumn{2}{|c|}{$\begin{array}{c}\text { Good OKAT }(> \\
60 \% \text { correct } \\
\text { answer) } \\
\end{array}$} & & \\
\hline & $\mathbf{N}$ & $\%$ & $\mathbf{N}$ & $\%$ & & \\
\hline \multicolumn{7}{|l|}{ Age } \\
\hline less than 40 years & 165 & 68.2 & 132 & 76.7 & \multirow{2}{*}{0.057} & \multirow{2}{*}{$0.64(0.42-1.01)$} \\
\hline 40 years and more & 77 & 31.8 & 40 & 23.3 & & \\
\hline \multicolumn{7}{|l|}{ Marital status } \\
\hline Unmarried & 81 & 33.5 & 55 & 32.0 & \multirow{2}{*}{0.75} & \multirow{2}{*}{$1.07(0.70-1.06)$} \\
\hline Married & 161 & 66.5 & 117 & 68.0 & & \\
\hline \multicolumn{7}{|l|}{ Educational level $^{\#}$} \\
\hline $\begin{array}{l}\text { University level and } \\
\text { lower }\end{array}$ & 170 & 70.2 & 66 & 38.4 & \multirow[t]{2}{*}{$<0.001 *$} & \multirow[t]{2}{*}{$3.79(2.50-5.73)$} \\
\hline Above university level & 72 & 29.8 & 106 & 61.6 & & \\
\hline \multicolumn{7}{|l|}{ Working status $^{\mathrm{I}}$} \\
\hline Not working & 96 & 39.7 & 42 & 24.4 & \multirow{2}{*}{$0.001 *$} & \multirow{2}{*}{$2.03(1.32-3.13)$} \\
\hline Working & 146 & 60.3 & 130 & 75.6 & & \\
\hline \multicolumn{7}{|c|}{ Source of information about osteoporosis } \\
\hline Friends $\mathbb{I}$ & 120 & 78.40 & 33 & 21.60 & $.000 *$ & \\
\hline Academic studying $\mathbb{I}$ & 92 & 67.60 & 44 & 32.40 & $.008 *$ & \\
\hline Mass media ${ }^{\mathbb{L}}$ & 71 & 35.50 & 129 & 64.50 & $.000 *$ & \\
\hline Physician ${ }^{\text {II }}$ & 59 & 67.00 & 29 & 33.00 & 0.065 & \\
\hline
\end{tabular}

(II) Chi-square test, (\#) fisher exact test, (*) P value $\leq 0.05$ is considered statistically significant. level.A p-value less than 0.05 is physicians (21.3\%) as described in Table considered statistically significant.

\section{Results}

The study included 414 adult women who agreed to answer the online questionnaire. The mean age was $35.6 \pm 10.6$ (18.0 85.0), most of them married (67.1\%), about half of them had university education $(51 \%)$, and most of them were working $(66.7 \%)$ as shown in Table 1.

All the surveyed women reported being familiar with OP, the predominant source forinformation was from Mass media (48.3\%), followed by friends (37\%), academic study (32.9\%), lastly from
2.

Table 3 outlined the women's answers to the OKAT items with the percentage of right answers for each item. More than $50 \%$ of the respondents correctly answered 13 items. The most frequent right answer was about the item "Osteoporosis leads to an increased risk of bone fractures" and the most wrong answer was about the item "Osteoporosis usually causes symptoms (e.g., pain) before fractures occur". the most do not know answer was about the item "A high salt intake is a risk factor for osteoporosis".

The mean of OKAT overall score was 10.5 \pm 3.4 , ranging from $(0.0-18.0)$; and the 
total knowledge percent score, $52.3 \pm 17.1$ $(0.0$ - 90.0). Less than half of studied women $(41.5 \%)$ achieved a percentage score ( $\geq 60 \%$ correct answer) as in Table 4 .
Table 5 demonstrates that the level of knowledge does not vary significantly with age. But it had a positive significant relation

Table 6: factors affecting the OP knowledge level among the studied women

\begin{tabular}{|c|c|c|c|c|}
\hline \multirow{2}{*}{ Variables } & \multirow{2}{*}{$P$ value } & \multirow{2}{*}{ AOR } & \multicolumn{2}{|c|}{ 95\% C.I. } \\
\hline & & & Lower & Upper \\
\hline $\begin{array}{l}\text { Age categories } \\
<40 \text { years** } \\
\geq 40 \text { years }\end{array}$ & .305 & .742 & .420 & 1.312 \\
\hline $\begin{array}{l}\text { Marital status } \\
\text { Unmarried** } \\
\text { Married } \\
\end{array}$ & .826 & .920 & .435 & 1.944 \\
\hline Number of children & .643 & 1.059 & .831 & 1.350 \\
\hline $\begin{array}{l}\text { Educational level } \\
\leq \text { University level } * * \\
\text { >Above university level }\end{array}$ & .000 & 4.591 & 2.587 & 8.146 \\
\hline $\begin{array}{l}\text { Working status } \\
\text { Not working } * * \\
\text { Working }\end{array}$ & .646 & .864 & .463 & 1.612 \\
\hline
\end{tabular}

(*) $P$ value $<0.001$, **reference group

with the educational level of respondents (high in postgraduate), and with working women. The source of information for women was statistically significant in relation to the level of knowledge where more correct answers were reported from those received information from Mass media, followed by physicians, academic study, lastly friends.

Table 6To study factors affecting the OP knowledge level among the studied women, a Binary logistic regression was conducted with the following predictor variables: age, marital status, Number of children, education and working status. results showed that the overall regression model was significant $\mathrm{X}^{2}$ $(5, \mathrm{~N}=414)=41.87, \mathrm{p}$ value $<0.001$, educational level was the only significant predictor, as having above university educational level associated with significant increase in the OP knowledge score $(\mathrm{AOR}=4.591 .95 \% \mathrm{CI}(2.587-8.146)$, $\mathrm{p}$ value $<0.001)$.

\section{Discussion}

The total number of women responding to the online questionnaire was 414 adult women living in Cairo with mean age of $35.6 \pm 10.6(18.0-85.0)$, most of them were married $(67.1 \%)$, about half of them had university education $(51 \%)$, and most of them were working $(66.7 \%)$.

In the current research, all the women studied reported having previous knowledge of OP, this result was almost similar to what was described in other previous studies conducted among adult women in Alexandria, Egypt (95.1\%), and another study in Canada (93\%), ${ }^{17,18}$ this similarity could be due to the fact that over half of the woman studied in these studies had university education. Contrarily, our finding was higher than previously observed in a population-based study held outin Singapore and another in rural Turkish regions as OP awareness among the studied women were $(57.9 \%$ and $60.8 \%$, respectively). ${ }^{19,20}$

The predominant source of OP information was mass media asit is reported by nearly half $(48 \%)$ of the womensurveyed, 
whilephysicians were statedto be a source of information by only(21.3\%). This result exposed a gap in the role of physicians in health education in our society and raising awareness. Such results were consistent with a survey conducted among adult womenin Saudi Arabia, Canada, American and Egypt $^{3,4,21,22}$ where the mass media was the primary source of knowledge in $(55.5 \%, 70 \%, 55 \%$ and $34 \%$ respectively) of the studied women.

Our study explored adult women's level of knowledge using valid and consistent OKAT questionnaires with strong psychometric properties, as it covers the core knowledge about osteoporosis. ${ }^{23,24}$ Results of various OKAT items showed that the most frequently correct answer $(90.6 \%)$ was about the item "Osteoporosis leads to an increased risk of bone fractures" this result was almost close with what was stated in another study performed in Saudi Arabia where 95\% of the woman studied correctly answered this question ${ }^{12}$ and lower thanwhat was reported in a study conducted among young female in Egypt as $50 \%$ of the participants mentioned that OP increased the risk of bone fractures, this dissimilarity could be due to that differences in age and educational level between the two studies. $^{22}$ On the other hand, the most frequent incorrect answer (79.5\%) was about the item "Osteoporosis usually causes symptoms (e.g., pain) before fractures occur", and this result was higher than what reported in previous studies in Egypt (33\%), Saudi Arabia (32.4\%). ${ }^{22,24}$

As noted in the current study results, several items received "don't know" answer from the women surveyed, where the response levels for this response ranged from $32.6 \%$ to $65.2 \%$; and these items were "Alcohol in moderation has little effect on osteoporosis, Family history of osteoporosis strongly predisposes a person to osteoporosis, high amount of bone loss in the 10 years following the onset of menopause, Cigarette smoking can contribute to osteoporosis, Hormone therapy prevents further bone loss at any age after menopause, There are no effective treatments for osteoporosis available, A high salt intake is a risk factor for osteoporosis, White women are at highest risk of fracture as compared to other race" most of these items mentioned as unknown by other studies conducted in Saudi Arabia and Egypt, ${ }^{22,24}$ this indicated that women with different age, educational level and residency are in essential need for improving their awareness about OP risk factors and the design of materials for health education should stress those items.

Regarding the total OKAT score and percentage, the results revealed moderate average of OP knowledge(score $=10.5 \pm$ 3.4 , percentage $=52.3 \pm 17.1$ ). Thisresult was close to results ofprevious studies carried out in Alexandriagovernorate, Egypt $($ score $=11.3 \pm 3.6),{ }^{18}$ Mansoura, the capital of Dakahliagovernorate, Egypt $(10.8 \pm 3.52),{ }^{25}$ another two studiesin Saudi Arabia where the mean scorepercentage in one of these studies was (percentage $=53.4$ $\pm 16.6)^{13}$ and the other study the mean score was $(10.4 \pm 3.2)^{24}$. On the other hand, the current score result was higher than the score percentage recorded in a study held out among young college women in Riyadh, KSA as the total score percentage was (45.04 \pm 14.1$)^{12}$ and another study conductedatZagazig District Egyptas results showed that adult women awareness about risk factors and preventative measures was very low, with about one-third having unsatisfactory levels of awareness, ${ }^{6}$ and was lower than that reported in another study among Turkish women as the percentage of total score was $(63.1 \pm 18.7) .{ }^{14}$ This disparity may be explained by differences in age and 
educational characteristics of the studied women.

The objective of this study was to evaluate the relationship between the various sociodemographic characteristics of the women surveyed and their total OKAT score.Our study results reveled that, good knowledge level was positively associated with highly educated and worked women, in agreement withprevious studies among adult women in Alexandria and Mansoura governorates Egypt, ${ }^{18,24}$ and in Saudi Arabia. ${ }^{15}$ These results could be linked to the fact that women who are highly educated and working are more competent to have easier and better access to high quality medical information than the women who are less educated.Furthermore, the regression analysis revealed that above university educational level associated with significant increase in OKAT total score.

Our analysis showed that women' information source was statistically significant associated with their knowledge level where more correct answers were stated from those received information from mass media, followed by physicians, academic study, lastly friends. This finding is a strong starting point for comprehensive health education initiativesacross mass media that adopted by the health sectors and planned based on evidence-basedresearch, this will have a significant impact on raising understanding of OP and helping to reduce morbidity and mortality from it. Comparing our findings with other studies findings revealed disagreement between it and what was reported in another study undertaken among young college women in Saudi Arabia $^{12}$ as information sources was not associated with the OKAT score. This difference could be attributed to that the last-mentioned study carried out among a group of women similar in their age and educational level; however, in our study, women have variation in their sociodemographic characteristics.

\section{Conclusion and recommendations:}

There was poor knowledge of osteoporosis among adult females studied in Cairo. Developing successful health education campaigns may be useful in increasing awareness about osteoporosis and its risk factors; thus, adopting healthy behaviors that avoid or reduce bone loss.

\section{Limitations:}

The research was performed only on volunteer adult women living in Cairo who accept filling out the online questionnaire; therefore, the results are not generalizable for all adult Egyptianwomen. Hence, further studies should be performed using a randomized sampling approach involving a large sample of adult women from various Governorates.

\section{Consent for publication}

"Not applicable"

\section{Funding}

No significant financial support for this work could have had an impact on its outcome.

\section{Acknowledgment:}

The authors wanted to express their deep gratitude to the respondents who generously provided their time and agreed to take part in this research.

\section{Disclosure statement}

The authors announce that they do not have competing interests.

\section{Data Availability Statement}

The data sets that were created and examined during the current study are available on request from the corresponding author. 


\section{References}

1. Werner P. Knowledge about osteoporosis: Assessment, correlates and outcomes. Osteoporos Int. 2005; 16(2):115-27

2. International foundation of osteoporosis, osteoporosis facts and statistics. 2017. Available from: https://www.iofbonehealth.org/facts-andstatistics/calcium-studies-map\#category-290. Accessed at: 19 August 2020.

3. Taha M. Prevalence of osteoporosis in Middle East systemic literature review. In: Proceedings of the 10th ECOO: 2011 April 1416. Cairo, Egypt. Available from: http://www.scribd.com/doc/53103901/Osteopo orosis-Cairo-April-2011-v1 . Accessed at: June 2, 2020.

4. Gheita T. A., Hammam N. International Journal of Clinical Rheumatology Epidemiology and awareness of osteoporosis: a viewpoint from the Middle East and North Africa. Int. J. Clin. Rheumatol. 2018; 13(3), 134-147.

5. Stransky M, RysavaL. Nutrition as prevention and treatment of Osteoporosis. Physio Res.2009;.58: Suppl1: S7-S11.

6. El Badawy AA, SharkawyGFEl, Fahmy HH, Demitry SR, Sherif NA, El Badawy SA.Awareness about osteoporosis among a sample of women and healthcare providers in Zagazig District Egypt. Egyptian Osteoporosis Prevention Society Conference, 2008.

7. HassanN.E., El ShebiniS. M., El-Masry S. A., Ahmed N. H., El Sherity S. Y., El Hamed E. R. A., Aboud H. T. Inter-relationship of awareness, knowledge, attitude, some socioeconomic variables, and osteoporosis in sample of Egyptian women. Open Access Macedonian Journal of Medical Sciences. 2019; 7(15), 2538-2544. Available from: https://doi.org/10.3889/oamjms. 2019.707. Accessed at: 19 August 2020.

8. OumerK.S., Liu Y., Yu Q., Wu F., Yang S.Awareness of osteoporosis among 368 residents in China: a cross-sectional study. BMC MusculoskeletDisord. 2020; 21: 197. Available from: https://doi.org/10.1186/s12891-020-03217-1. Accessed at: 21 August 2020.
9. International Osteoporosis Foundation. Three stages to unbreakable bone: vitamin d, calcium, and exercise. 2011. Availablefrom:https://www.iofbonehealth.or $\mathrm{g} /$ sites/default/files/PDFs/WOD\%20Reports/ WOD11_Report.pdf. Accessed at: 19 August 2020.

10.Kasper MJ, Peterson MG, Allegrante JP. The need for comprehensive educational osteoporosis prevention programs for young women: Results from a second osteoporosis prevention survey. Arthritis Rheum. 2001; 45(1):28-34.

11.Winzenberg TM, Oldenburg B, Frendin S, Jones $\mathrm{G}$. The design of a valid and reliable questionnaire to measure osteoporosis knowledge in women: The Osteoporosis Knowledge Assessment Tool (OKAT). BMC MusculoskeletDisord. 2003; 4:17.

12. Alshareef SH, Alwehaibi A, Alzahrani A, Faqihi A, Alkenani A, Alfentoukh M, et al. Knowledge and Awareness about Risk Factors of Osteoporosis among Young College Women at a University in Riyadh, KSA. J Bone Res. 2018; 6 (2): 194.

13.Khan J. A., McGuigan F. E., Akesson K. E., Ahmed Y. M., Abdu F., Rajab H., Albaik M. Osteoporosis knowledge and awareness among university students in Saudi Arabia. Arch Osteoporos. 2019; 14(1).

14.Ungan M, Tumer M. Turkish women's knowledge of osteoporosis. FamPract. 2001; 18(2):199-203.

15.Alamri FA., Saeedi MY, Mohamed A, Barzanii A, Aldayel M, Ibrahim AK. Knowledge, Attitude, And practice of osteoporosis among Saudis: A CommunityBased study. J Egypt Public Health. 2015; 90 (4):171-7.

16.Sayed-Hassan RM, Bashour HN. The reliability of the Arabic version of osteoporosis knowledge assessment tool (OKAT) and the osteoporosis health belief scale (OHBS). BMC Res Notes. 2013; 6:138.

17.Juby AG, Davis P. A prospective evaluation of the awareness, knowledge, risk factors and current treatment of osteoporosis in a cohort of elderly subjects. Osteoporos Int. 2001; 12 (8):617-22. 
18.El-Tawab, S. S., Saba, E. K. A., Elweshahi, H. M. T., Ashry, M. H. (2016). Knowledge of osteoporosis among women in Alexandria (Egypt): A community-based survey. Egypt Rheumatol. 2016; 38(3): 225-31.

19.Iolascon G, Gimigliano F, Malavolta N, Tarantino U, Fornari R, Greco E, et al. Effectiveness of teriparatide treatment on back pain-related functional limitations in individuals affected by severe osteoporosis: a prospective pilot study. Clin Cases Miner Bone Metab. 2012; 9(3):161-5.

20.Saw SM, Hong CY, Lee J, Wong ML, Chan MF, Cheng A, et al. Awareness and health beliefs of women towards osteoporosis. Osteoporos Int. 2003; 14 (7):595-601.

21.El-Tohami K., Sami W., Eidan A., Mubarak M., Alotaibi F. Study of Knowledge, Attitude and Practice of Osteoporosis among Adult Women in Majmaah City, Saudi Arabia. IJHRS. 2015; 4(3):185-92.
22.Wahba S. A., Abd El-Shaheed A., Tawheed M. S., Mekkawy A. A.,Arrafa A. M.Osteoporosis Knowledge, Beliefs, and Behaviors Among Egyptian Female Students. JASMR, 2010; 5(2):12-14. http://www.asmr.eg.net

23.Tadic I, Stevanovic D, Tasic L, VujasinovicStupar N. Development of a shorter version of the osteoporosis knowledge assessment tool. Women Health. 2012; 52(1): $18-31$.

24.Almalki N, Algahtany F, Alswat K. Osteoporosis knowledge assessment among medical interns. Am J Res Commun. 2016; 4(1): 1-14.

25.El-Masry R, Elkhawaga G, El-Gilany A, Alam R.R. Knowledge and Health Beliefs of Elderly Women toward Osteoporosis in Mansoura, Egypt. Progress in Medical Sciences. 2018; 2(2): 27-33. 